\title{
Association of adverse childhood experiences with lifetime mental and substance use disorders among men and women aged $50+$ years
}

\author{
Namkee G. Choi, ${ }^{1}$ Diana M. DiNitto, ${ }^{1}$ C. Nathan Marti ${ }^{1}$ and Bryan Y. Choi ${ }^{2}$ \\ ${ }^{1}$ The University of Texas at Austin School of Social Work, Austin, Texas 78712, USA \\ ${ }^{2}$ Department of Emergency Medicine, MPH Brown University, Providence, Rhode Island 02903, USA
}

ABSTRACT

Background: Given growing numbers of older adults with mental and substance use disorders (MSUDs), this study examined the association between ten types of adverse childhood experiences (ACEs) and lifetime MSUDs among those aged $50+$.

Methods: Data $(\mathrm{N}=14,738$ for the $50+$ age group) came from the 2012 to 2013 National Epidemiologic Survey on Alcohol and Related Conditions. Using multivariable binary logistic regression analyses, we examined relationships between ten ACEs and six lifetime MSUDs (major depressive disorder (MDD) and anxiety, post-traumatic stress, alcohol use, drug use, and nicotine use disorders). Gender differences were examined using tests of interaction effects and gender-separate logistic regression models.

Results: Of the sample, $53.2 \%$ of women and $50.0 \%$ of men reported at least one ACE. For both genders, parental/other adult's substance abuse was the most prevalent (22.6\%), followed by physical abuse, and emotional neglect. Child abuse and neglect and parental/other adult's mental illness and substance abuse had small but consistently significant associations with MSUDs (e.g., odds ratio = 1.28, 95\% CI = 1.12-1.46 for parental/other adult's substance misuse and MDD). Although the relationship between total number of ACEs and MSUDs was cumulative for both men and women, the associations of physical abuse, sexual abuse, emotional neglect, and parental separation/divorce with MSUDs were stronger among men.

Conclusions: This study underscores the significant yet modest association between ACEs and lifetime MSUDs in late life. More research is needed to investigate why ACEs seem to have greater effects on older men and to discern the sources of gender differences in ACEs' effects.

Key words: adverse childhood experiences, aging, mental disorders, substance use disorders

\section{Introduction}

A growing body of evidence points to the powerful long-term influence of adverse childhood experiences (ACEs: childhood maltreatment and family dysfunction) on physical health (e.g. cardiac diseases, COPD, diabetes, liver disease, obesity, sleep disturbance, and death before age 65 years), mental health (e.g. mood, anxiety, and posttraumatic stress disorders (PTSDs), schizophrenia, and suicidal ideation), substance use disorders, and health risk behaviors (e.g. smoking, sexual risk behaviors, and intimate partner violence) in

Correspondence should be addressed to: Namkee G. Choi, The University of Texas at Austin School of Social Work, 1925 San Jacinto Blvd, Austin, Texas 78759, USA. Email: nchoi@austin.utexas.edu Received 6 May 2016; revision requested 8 Aug 2016; revised version received 21 Sep 2016; accepted 24 Sep 2016. First published online 26 October 2016. adulthood (Dube et al., 2003; Tamayo et al., 2010; Bellis et al., 2014; Kalmakis and Chandler, 2015). Previous research on ACEs shows that, in addition to each ACE's negative impact on physical and mental health outcomes, there is a graded relationship between the cumulative number of ACEs and health conditions, depression, and health risk behaviors among adults (Anda et al., 2002; Dube et al., 2003; Chapman et al., 2004; Anda et al., 2006). Previous research also shows that ACEs are more common among women than among men and that there are significant gender differences in the association between different types of ACEs and mental and substance use disorders (MSUDs) (Keyes et al., 2012; Cavanaugh et al., 2015). For example, physical abuse was associated with mental disorders in women but with substance use disorders in men (Keyes et al., 2012), 
which may also reflect higher rates of mood and anxiety disorders among women and higher rates of substance use disorders among men (Kessler et al., 2005; Lev-Ran et al., 2013).

Although direct causal relationships are impossible to establish, severe stress or traumatization from ACEs may result in long-lasting neurobiological changes and vulnerability to stress-related health conditions and mental disorders, including addiction (Brady and Back, 2012). ACEs' strong association with physical/mental health problems is often explained by interconnectivity among genetic dispositions, epigenetic mechanisms, stressrelated hormonal systems (e.g. dysregulation of the hypothalamus-pituitary-adrenal axis, especially for its end product, cortisol), and immune parameters (Ehlert, 2013; McCrory and Mayes, 2015). Selfmedication or tension-reduction hypotheses related to substance misuse also suggest that ACEs lead to early initiation of substance use as a coping mechanism, which can further contribute to the cyclical interplay of risky behaviors, more stress, and more substance misuse (Whitesell et al., 2009). Adversity occurring early in key developmental stages is also likely to interrupt developmental processes, causing disorganization in brain systems that interferes with normal psychological growth (Whitesell et al., 2009; McCrory and Mayes, 2015). Compromised child development interferes with the usual acquisition of self-capacities such as affect regulation skills, and impaired affect regulation leads to reliance on avoidance coping strategies including substance abuse, which further prevents the development of self-regulation capacities in a vicious cycle (Briere and Elliott, 2003). Childhood adversity may also be a marker of more prolonged and chronic exposure that is likely to lead to more lasting and profound negative effects than isolated encounters (Whitesell et al., 2009). Researchers have also found that the relationship between ACEs and the subsequent development of substance misuse may be partially mediated by PTSD, mood, and anxiety disorders from ACEs (Douglas et al., 2010; Cross et al., 2015).

Compared to younger adults, older age cohorts were less likely to experience familial incarceration, substance use, and divorce during childhood, which may partially explain why they report fewer ACEs (Dube et al., 2003; Centers for Disease Control and Prevention (CDC), 2010). For example, an analysis of data $(\mathrm{N}=26,229)$ from the 2009 ACE module of the Behavioral Risk Factor Surveillance System shows that $43.3 \%$ of those aged $55+$ reported at least one ACE, compared to $64.5 \%$ of the $18-24$ age group, $69.9 \%$ of the $25-34$ age group, $64.3 \%$ of the $35-44$ age group, and $58.2 \%$ of the $45-54$ age group (CDC, 2010). Despite reporting fewer
ACEs, the growing population of older adults is reporting higher rates of MSUDs than previous older adult cohorts. Older adults' increasing rates of substance misuse is often attributed to a more permissive culture of substance use among the baby boomers who are joining the ranks of older adults (Choi et al., 2015). However, little research has examined childhood developmental and environmental risk factors that may have also contributed to MSUDs in the growing older-adult population.

Using nationally representative, U.S. population-based epidemiologic data, we first examined (1) the prevalence of ACEs in the $50+$ age group by gender and (2) the association of each type of ACE and the total number of ACEs with lifetime MSUDs (major depressive disorder (MDD), anxiety disorder, PTSD, alcohol use disorder, drug use disorder, and nicotine use disorder). Based on previous study findings (Chapman, et al., 2004; Douglas et al., 2010; Keyes et al., 2012; Cavanaugh et al., 2015; Cross et al., 2015), our hypotheses were controlling for sociodemographic variables, (H1a) childhood psychological, physical, and sexual abuse and parental/other household member mental illness and substance abuse will be significantly associated with all six types of lifetime MSUDs; (H1b) the association between these ACEs and lifetime mental disorders will be stronger among women than among men, whereas the association between these ACEs and lifetime substance use disorders will be stronger among men; $(\mathrm{H} 2 \mathrm{a})$ the total number of ACEs will be significantly associated with all six types of lifetime MSUDs; and (H2b) the association between the number of ACEs and lifetime mental disorders will be stronger among women than among men, whereas the association between the number of ACEs and lifetime substance use disorders will be stronger among men. Additionally, based on previous research that showed PTSD as a partial mediator (Cross et al., 2015), we tested whether including lifetime PTSD as a covariate in multivariate models weakened the association between the number of ACEs and lifetime MDD, anxiety disorder, and substance use disorders.

\section{Methods}

\section{Data and sample}

Data came from the 2012-2013 U.S. National Epidemiologic Survey on Alcohol and Related Conditions (NESARC-III), a national probability sample survey of the U.S. civilian noninstitutionalized population aged $18+$ years 
( $N=36,309$ ), sponsored by the National Institute on Alcohol Abuse and Alcoholism (NIAAA). Using computer-assisted personal interviewing, data were collected on alcohol and other substance use, substance use disorders, and related physical and mental disabilities. The semi-structured diagnostic interview used to collect information was the NIAAA Alcohol Use Disorder and Associated Disabilities Interview Schedule (AUDADIS-5). The AUDADIS-5 was used to identify pastyear, prior-to-past-year, and lifetime DSM-5 diagnoses of MSUDs. In NESARC-III's multistage probability sampling, primary sampling units were individual counties or, in some small rural counties, combined contiguous counties; secondary sampling units were groups of census-defined blocks; tertiary sampling units were households within sampled secondary sampling units, from which eligible adult respondents were randomly selected, with Hispanic, Black, and Asian individuals oversampled. The NESARC website contains detailed descriptions of sampling and interviewer field methods (Grant et al., 2015). In this study, we focused on the 14,738 individuals aged $50+$ sampled.

\section{Measures}

ACEs: NESARC-III contains questions adapted from the original CDC-Kaiser ACE Study (Felitti et al., 1998; Anda et al., 2006) and the ongoing CDC's Behavioral Risk Factor Surveillance System ACE studies (CDC, 2016). They include questions adapted from the Childhood Trauma Questionnaire (Bernstein et al., 1994; Fink et al., 1995), the Conflict Tactics Scale (Straus, 1979), and questions other investigators have used to assess childhood sexual abuse (Wyatt, 1985). In NESARC-III, ACEs are experiences that occur before age 18. In keeping with the ACEs calculator (http://acestudy.org/the-ace-score.html), we examined ten ACEs (i.e. including emotional and physical neglect) rather than the eight ACEs that were used in the CDC-Kaiser and Behavioral Risk Factor Surveillance System ACE studies): (1) psychological abuse; (2) physical abuse; (3) sexual abuse; (4) emotional neglect; (5) physical neglect; (6) witnessing mother or other adult female treated violently; (7) parent's or other household member's substance abuse; (8) parent's or other household member's mental illness, suicide attempt, or suicide (mental illness hereafter); (9) parent's or other household member's incarceration; and (10) parental separation or divorce. Consistent with the ACEs calculator, reports were coded as 1 for experienced or 0 for did not experience the ACE. The total number of
ACEs represents the summed score $(0-10)$ as a continuous variable.

Mental and substance use disorders (MSUDs): In this study, we examined three mental disorders: (1) lifetime MDD, (2) any anxiety disorder (specific phobia, social phobia, panic disorder, agoraphobia, or generalized anxiety disorder), and (3) PTSD, and three substance use disorders: (i) alcohol use disorder, (ii) drug (cannabis, sedative, opioid, cocaine, stimulant, hallucinogen, inhalant/solvent, club drug, heroin, and/or other drug) use disorder, and (iii) nicotine use disorder.

Sociodemographic characteristics as controls: We included chronological age, gender, race/ethnicity (non-Hispanic White, non-Hispanic Black, Hispanic, non-Hispanic Asian/Pacific Islander (Asian American hereafter), and American Indian/Alaska Native (American Indian hereafter)), marital status (married/cohabiting or not), education (college degree or not), and whether or not family received welfare (including food stamps, aid to families with dependent children or temporary assistance for needy families) before age 18 as a proxy for childhood family's economic status.

\section{Analysis}

All analyses were conducted with Stata/MP 14's svy function to account for NESARC-III's multistage probability sampling design. Stata's subpop command was used for all subsample analyses (e.g. those aged $50+$ ) to ensure that variance estimates incorporate the full sampling design. All estimates presented in this study are weighted except sample sizes. First, we used $\chi^{2}$ and t-tests to compare sociodemographic characteristics, ACE prevalence, and lifetime and past-year MSUDs between genders. Second, we used multivariable binary logistic regression analysis, reporting odds ratios (OR) and 95\% confidence intervals (CI), to test $\mathrm{H} 1 \mathrm{a}$ and $\mathrm{H} 1 \mathrm{~b}$ (association of each type of ACE with each of six lifetime MSUDs and gender difference). In the first model, the main effects of each type of ACE were tested; in the second model, interaction effects between gender and each type of ACE were tested. To elucidate results from the interaction effect analyses, we also conducted gender-separate logistic regression analyses. Third, we used multivariable binary logistic regression analyses to test $\mathrm{H} 2 \mathrm{a}$ and $\mathrm{H} 2 \mathrm{~b}$ (association of the total number of ACEs (0-10) with each of the six lifetime MSUDs and gender difference). In the first model, the main effects of the total number of ACEs were tested, and in the second model, interaction effects between gender and the total number of ACEs were tested. Then, controlling for lifetime PTSD, we examined the association 
of the number of ACEs with each of other five lifetime MSUDs. As a preliminary diagnostic, variance inflation factor (VIF) (using a cut-off of 2.50; Allison, 2015) from linear regression models was used to assess multicollinearity among ACEs (i.e. the relationships among covariates). VIF diagnostics indicated that multicollinearity was not a concern. The highest VIF was 1.52 for psychological abuse.

\section{Results}

\section{Sample characteristics}

Table 1 shows that men ( $46.8 \%$ of the sample) were about one-year younger and more likely to be married and college educated than women $(53.3 \%$ of the sample), but there were no gender differences in racial/ethnic composition and rates of family welfare receipt before age 18. With respect to ACEs, $46.8 \%$ of women and $50.0 \%$ of men reported none, $34.7 \%$ of women and $35.7 \%$ of men reported one-two, $6.6 \%$ of women and $6.0 \%$ of men reported three, and $11.9 \%$ of women and $8.4 \%$ of men reported four or more. For both genders, the most prevalent ACE was parental/other adult's substance abuse $(23.8 \%$ of women and $21.3 \%$ of men, $\mathrm{p}=0.004$ ), followed by physical abuse ( $17.5 \%$ of women and $19.6 \%$ of men, $\mathrm{p}=0.001$ ), and emotional neglect $(17.6 \%$ of women and $15.9 \%$ of men, $p=0.020$ ). Sexual abuse was more than twice as prevalent in women $(15.7 \%)$ than in men $(6.4 \%)(\mathrm{p}<0.001)$. Nearly $10 \%$ of the sample, respectively, reported psychological abuse and witnessing domestic violence and about $6 \%$ reported parental/other adult's mental illness, with higher rates among women than among men. There was no significant gender difference in reports of parental/other adult's incarceration and parental divorce. Regarding lifetime mental disorders, $24.4 \%$ of the women and $13.5 \%$ of the men had MDD; $21.2 \%$ of women and $12.2 \%$ of men had anxiety disorder; and $6.1 \%$ of women and $3.7 \%$ of men had PTSD (all at $\mathrm{p}<0.001$ ). Regarding lifetime substance use disorders, $14.6 \%$ of women and $29.5 \%$ of men had alcohol use disorder; $4.7 \%$ of women and $8.7 \%$ of men had drug use disorder; and $22.4 \%$ of women and $31.7 \%$ of men had nicotine use disorder (all at $\mathrm{p}<0.001$ ).

Table 1 also shows that among those with at least one ACE, $44.8 \%$ of women and $42.6 \%$ of men $(p=0.120)$ reported parental/other adult's substance abuse; $32.8 \%$ women and $39.2 \%$ of men $(\mathrm{p}<0.001)$ reported physical abuse; $20.0 \%$ of women and $16.6 \%$ of men $(\mathrm{p}=0.002)$ reported psychological abuse; $29.5 \%$ of women and $12.9 \%$ of men $(p<0.001)$ reported sexual abuse; $20.0 \%$ of women and $16.3 \%$ of men $(p<0.001)$ reported witnessing domestic violence; and $12.3 \%$ of women and $9.9 \%$ of men $(p=0.006)$ reported parental/other adult's mental illness. In addition to parental/other adult's substance abuse, reports of emotional neglect, physical neglect, parental/other adult's incarceration, and parental divorce did not significantly differ between genders. Regarding lifetime mental disorders, $31.2 \%$ of women and $16.7 \%$ of men had MDD; $27.2 \%$ of women and $16.1 \%$ of men had anxiety disorder; and $9.7 \%$ of women and $5.3 \%$ of men had PTSD (all at p < 0.001). Regarding lifetime substance use disorders, $19.5 \%$ of the women and $36.4 \%$ of the men had alcohol use disorder; $7.0 \%$ of women and $11.9 \%$ of men had drug use disorder; and $27.4 \%$ of women and $37.9 \%$ of men had nicotine use disorder (all at $\mathrm{p}<0.001)$.

\section{Association of ACEs with mental disorders}

Table 2 shows that controlling for sociodemographic characteristics (age, gender, race/ethnicity, education, marital status, and welfare receipt before age 18), psychological abuse, physical abuse, sexual abuse, emotional neglect, and physical neglect were significantly associated with increased odds of lifetime MDD, anxiety disorder, and PTSD. Parental/other adult's substance abuse was also associated with increased odds of MDD and anxiety disorders and marginally associated with PTSD $(p=0.051)$, and parental/other adult's mental illness was associated with MDD and anxiety disorders. Witnessing domestic violence and parental/other adult's incarceration was associated with increased odds of PTSD only. ORs for psychological and physical abuse and neglect, parental/other adult's substance abuse, mental illness, and incarceration tended to be small (ranging from 1.17 to 1.80 ). With respect to sexual abuse, the greatest OR was for PTSD $(\mathrm{OR}=2.21,95 \% \mathrm{CI}=1.75-2.78)$, and $\mathrm{ORs}$ for $\operatorname{MDD}(\mathrm{OR}=1.58,95 \% \quad \mathrm{CI}=1.35-1.86)$, and anxiety disorder $(\mathrm{OR}=1.52,95 \% \mathrm{CI}=1.31-1.76)$ were similar to each other.

Introduction of the interaction terms between gender and ACEs in the logistic regression models did not substantially change the associations between ACEs and mental disorders. However, some results were notable. First, the main effects of physical abuse were no longer significant for MDD and anxiety disorder; the main effects of emotional neglect were no longer significant for anxiety disorder and PTSD; and the main effects of witnessing domestic violence were no longer significant for PTSD. However, in each case, the reduction in the odds ratios was slight 
Table 1. Sample characteristics

\begin{tabular}{|c|c|c|c|c|c|c|c|}
\hline & \multicolumn{4}{|c|}{ ALL IN THE $50+$ AGE GROUP $(\mathrm{N}=14,738)$} & \multicolumn{3}{|c|}{ THOSE With at LEAST ONE ACE $(\mathrm{N}=7,879)$} \\
\hline & ALL $100 \%$ & FEMALE $53.25 \%$ & MALE $46.75 \%$ & $\mathrm{p}$ & FEMALE $54.81 \%$ & MALE $45.19 \%$ & $\mathrm{p}$ \\
\hline Age $(M, S E)$ & $63.53(0.12)$ & $64.00(0.15)$ & $62.99(0.15)$ & $<0.001$ & $62.85(0.18)$ & $62.42(0.20)$ & 0.079 \\
\hline Race/ethnicity & & & & 0.219 & & & 0.068 \\
\hline Non-Hispanic White & 75.05 & 74.65 & 75.50 & & 75.27 & 73.79 & \\
\hline Non-Hispanic Black & 10.03 & 10.65 & 9.34 & & 11.17 & 10.68 & \\
\hline Hispanic & 9.01 & 8.99 & 9.02 & & 9.09 & 9.47 & \\
\hline Non-Hispanic Asian & 4.50 & 4.36 & 4.67 & & 3.08 & 4.04 & \\
\hline American Indian & 1.41 & 1.36 & 1.46 & & 1.93 & 2.01 & \\
\hline Marital status & & & & $<0.001$ & & & $<0.001$ \\
\hline Married & 63.38 & 56.33 & 71.41 & & 55.32 & 68.70 & \\
\hline Widowed & 12.64 & 18.57 & 5.89 & & 16.19 & 5.56 & \\
\hline Divorced & 17.52 & 19.21 & 15.58 & & 22.81 & 17.81 & \\
\hline Never married & 6.46 & 5.89 & 7.12 & & 5.68 & 7.93 & \\
\hline Have college degree & 29.45 & 26.44 & 32.89 & $<0.001$ & 24.25 & 28.68 & 0.002 \\
\hline $\begin{array}{l}\text { Number of chronic medical } \\
\text { conditions }^{\mathrm{a}}\end{array}$ & $1.25(0.02)$ & $1.30(0.02)$ & $1.20(0.02)$ & $<0.001$ & $1.43(0.03)$ & $1.28(0.02)$ & $<0.001$ \\
\hline Family on welfare before age 18 & 8.65 & 8.26 & 9.09 & 0.060 & 12.33 & 12.61 & 0.728 \\
\hline \multicolumn{8}{|c|}{ Adverse childhood experiences (ACEs) } \\
\hline Total number of ACEs (M,SE) & $1.19(0.02)$ & $1.28(0.03)$ & $1.08(0.03)$ & $<0.001$ & $2.41(0.03)$ & $2.15(0.03)$ & $<0.001$ \\
\hline 0 & 48.31 & 46.80 & 50.03 & & $\mathrm{n} / \mathrm{a}$ & $\mathrm{n} / \mathrm{a}$ & \\
\hline 1 & 23.97 & 23.46 & 24.55 & & 44.10 & 49.14 & \\
\hline 2 & 11.19 & 11.26 & 11.11 & & 21.18 & 22.24 & \\
\hline 3 & 6.31 & 6.62 & 5.95 & & 12.45 & 11.90 & \\
\hline $4+$ & 10.22 & 11.86 & 8.36 & & 22.27 & 16.72 & \\
\hline Psychological abuse & 9.55 & 10.65 & 8.30 & $<0.001$ & 20.02 & 16.61 & 0.002 \\
\hline Physical abuse & 18.46 & 17.46 & 19.61 & 0.001 & 32.82 & 39.24 & $<0.001$ \\
\hline Sexual abuse & 11.36 & 15.69 & 6.43 & $<0.001$ & 29.50 & 12.87 & $<0.001$ \\
\hline Emotional neglect & 16.79 & 17.59 & 15.88 & 0.020 & 33.07 & 31.78 & 0.294 \\
\hline Physical neglect & 6.85 & 7.43 & 6.18 & 0.019 & 13.96 & 12.37 & 0.118 \\
\hline Witnessed domestic violence & 9.46 & 10.62 & 8.13 & $<0.001$ & 19.97 & 16.26 & 0.001 \\
\hline $\begin{array}{l}\text { Parental/other adult's substance } \\
\text { use problems }\end{array}$ & 22.64 & 23.84 & 21.27 & 0.004 & 44.82 & 42.56 & 0.120 \\
\hline $\begin{array}{l}\text { Parental/other adult's mental } \\
\text { health problems }\end{array}$ & 5.81 & 6.57 & 4.93 & $<0.001$ & 12.34 & 9.89 & 0.006 \\
\hline $\begin{array}{l}\text { Parental/other adult's } \\
\text { incarceration }\end{array}$ & 4.74 & 5.08 & 4.34 & 0.071 & 9.55 & 8.69 & 0.253 \\
\hline Parental separation/divorce & 12.90 & 13.23 & 12.51 & 0.261 & 24.88 & 25.04 & 0.883 \\
\hline
\end{tabular}


(i.e. a decrease of 0.06-0.14) after introducing the interaction term. Second, the interaction effects of parental separation/divorce and male gender were significant for MDD, i.e. the association was stronger for men than for women. Third, the main effect of family members' incarceration on anxiety disorder was weaker for men than for women.

The gender-separate logistic regression analyses (not shown in tables) confirmed the following four findings for men only. First, physical abuse was a significant factor for $\mathrm{MDD}(\mathrm{OR}=1.33,95 \%$ $\mathrm{CI}=1.05-1.68)$ and anxiety disorder $(\mathrm{OR}=1.51$, $95 \% \mathrm{CI}=1.18-1.94)$. Second, emotional neglect was a significant factor for anxiety disorder $(\mathrm{OR}=1.33,95 \% \mathrm{CI}=1.08-1.65)$ and PTSD $(\mathrm{OR}=1.73,95 \% \mathrm{CI}=1.24-2.42)$. Third, parental separation/divorce was associated with increased odds of $\mathrm{MDD} \quad(\mathrm{OR}=1.44, \quad 95 \% \quad \mathrm{CI}=1.16-$ 1.79). Fourth, family members' incarceration was associated with decreased odds of anxiety disorder $(\mathrm{OR}=0.60,95 \% \mathrm{CI}=0.42-0.87)$.

Of the control variables, being older, male, and married/cohabiting were associated with lower odds of having each of the three mental disorders. Being Black, Hispanic, or Asian, compared to nonHispanic White, was also associated with lower odds of MDD and anxiety disorders, whereas being American Indian was associated with higher odds of PTSD. College education was associated with higher odds of MDD, and welfare receipt before age 18 was associated with higher odds of anxiety disorder.

\section{Association of ACEs with substance use disorders}

Table 3 shows that physical abuse, sexual abuse, and parental/other adult's substance abuse were significantly associated with increased odds of all three lifetime substance use disorders (alcohol, drug, and nicotine), with parental/other adult's substance abuse being associated with somewhat greater odds of alcohol use disorder $(\mathrm{OR}=1.83,95 \%$ $\mathrm{CI}=1.60-2.10)$ than other ACEs. Parental/other adult's mental illness also was a significant factor for alcohol use disorder and drug use disorder and marginally significant for nicotine use disorder $(p=0.056)$. Psychological abuse was associated with increased odds of drug use disorder and nicotine use disorder, and parental divorce was associated with nicotine use disorder. Emotional neglect, physical neglect, witnessing domestic violence, and parental/other adult's incarceration were not significant factors for any substance use disorder.

Introducing interaction terms between gender and ACEs in the logistic regression models did 
Table 2. Adverse childhood experiences and lifetime mental disorders among the 50+ age group: binary logistic regression results

\begin{tabular}{|c|c|c|c|c|c|c|}
\hline & \multicolumn{2}{|c|}{ LIFETIME MDD } & \multicolumn{2}{|c|}{ LIFETIME ANXIETY DISORDERS } & \multicolumn{2}{|c|}{ LIFETIME PTSD } \\
\hline & OR $(95 \% \mathrm{CI})$ & OR $(95 \% \mathrm{CI})$ & OR $(95 \% \mathrm{CI})$ & OR $(95 \% \mathrm{CI})$ & OR $(95 \% \mathrm{CI})$ & OR $(95 \% \mathrm{CI})$ \\
\hline Age & $0.97(0.96-0.97)^{* * *}$ & $0.97(0.96-0.97)^{* * *}$ & $0.98(0.97-0.98)^{* * *}$ & $0.98(0.97-0.98)^{* * *}$ & $0.97(0.96-0.98)^{* * *}$ & $0.97(0.96-0.98)^{* * *}$ \\
\hline Male & $0.50(0.45-0.56)^{* * *}$ & $0.47(0.41-0.54)^{* * *}$ & $0.55(0.48-0.62)^{* * *}$ & $0.51(0.43-0.60)^{* * *}$ & $0.71(0.58-0.86)^{* *}$ & $0.63(0.47-0.85)^{* *}$ \\
\hline Black & $0.48(0.42-0.56)^{* * *}$ & $0.48(0.42-0.56)^{* * *}$ & $0.63(0.54-0.72)^{* * *}$ & $0.63(0.54-0.72)^{* * *}$ & $0.99(0.79-1.24)$ & $0.98(0.79-1.23)$ \\
\hline Hispanic & $0.64(0.54-0.77)^{* * *}$ & $0.65(0.54-0.77)^{* * *}$ & $0.61(0.51-0.73)^{* * *}$ & $0.61(0.51-0.73)^{* * *}$ & $0.76(0.58-1.00)$ & $0.77(0.58-1.01)$ \\
\hline Asian & $0.44(0.31-0.62)^{* * *}$ & $0.44(0.30-0.62)^{* * *}$ & $0.41(0.29-0.58)^{* * *}$ & $0.41(0.29-0.58)^{* * *}$ & $0.47(0.23-0.94)^{*}$ & $0.47(0.23-0.96)^{*}$ \\
\hline American Indian & $1.14(0.81-1.60)$ & $1.13(0.81-1.59)$ & $1.22(0.86-1.73)$ & $1.20(0.84-1.70)$ & $2.57(1.54-4.28)^{* * *}$ & $2.60(1.57-4.30)^{* * *}$ \\
\hline College degree & $1.20(1.08-1.33)^{* *}$ & $1.20(1.08-1.34)^{* *}$ & $0.91(0.79-1.03)$ & $0.90(0.79-1.03)$ & $0.88(0.72-1.07)$ & $0.88(0.72-1.07)$ \\
\hline Married/cohabiting & $0.67(0.62-0.73)^{* * *}$ & $0.67(0.62-0.73)^{* * *}$ & $0.82(0.74-0.91)^{* * *}$ & $0.82(0.74-0.91)^{* * *}$ & $0.72(0.59-0.87)^{* *}$ & $0.72(0.60-0.87)^{* *}$ \\
\hline Family on welfare before 18 & $1.09(0.96-1.38)$ & $1.10(0.93-1.30)$ & $1.26(1.07-1.50)^{* *}$ & $1.27(1.07-1.50)^{* *}$ & $1.29(0.98-1.69)$ & $1.31(1.00-1.72)$ \\
\hline \multicolumn{7}{|l|}{ Adverse childhood experiences } \\
\hline Psychological abuse & $1.52(1.21-1.90)^{* * *}$ & $1.42(1.10-1.83)^{* *}$ & $1.51(1.23-1.85)^{* * *}$ & $1.44(1.13-1.83)^{* *}$ & $1.40(1.06-1.84)^{*}$ & $1.42(1.04-1.94)^{*}$ \\
\hline Physical abuse & $1.23(1.06-1.43)^{* *}$ & $1.17(0.97-1.42)$ & $1.27(1.07-1.50)^{* *}$ & $1.13(0.91-1.41)$ & $1.58(1.20-2.08)^{* *}$ & $1.71(1.24-2.35)^{* *}$ \\
\hline Sexual abuse & $1.58(1.35-1.86)^{* * *}$ & $1.54(1.30-1.84)^{* * *}$ & $1.52(1.31-1.76)^{* * *}$ & $1.54(1.33-1.78)^{* * *}$ & $2.21(1.75-2.78)^{* * *}$ & $2.34(1.82-3.00)^{* * *}$ \\
\hline Emotional neglect & $1.17(1.01-1.36)^{*}$ & $1.23(1.05-1.45)^{*}$ & $1.22(1.07-1.40)^{* *}$ & $1.17(0.97-1.41)$ & $1.42(1.14-1.77)^{* *}$ & $1.26(0.95-1.67)$ \\
\hline Physical neglect & $1.25(1.01-1.55)^{*}$ & $1.15(0.90-1.46)$ & $1.58(1.28-1.95)^{* * *}$ & $1.77(1.34-2.33)^{* * *}$ & $1.80(1.31-2.47)^{* * *}$ & $1.53(1.09-2.14)^{*}$ \\
\hline Witnessed domestic violence & $0.90(0.75-1.09)$ & $0.97(0.76-1.24)$ & $1.01(0.81-1.26)$ & $1.04(0.80-1.35)$ & $1.36(1.05-1.75)^{*}$ & $1.30(0.95-1.78)$ \\
\hline $\begin{array}{l}\text { Parental/other adult's substance } \\
\text { abuse }\end{array}$ & $1.28(1.12-1.46)^{* * *}$ & $1.27(1.09-1.48)^{* *}$ & $1.33(1.17-1.51)^{* * *}$ & $1.30(1.11-1.52)^{* *}$ & $1.25(1.00-1.55) \ddagger$ & $1.27(0.96-1.69)$ \\
\hline $\begin{array}{l}\text { Parental/other adult's mental } \\
\text { illness }\end{array}$ & $1.40(1.13-1.72)^{* *}$ & $1.50(1.16-1.94)^{* *}$ & $1.64(1.36-1.98)^{* * *}$ & $1.67(1.30-2.13)^{* * *}$ & $1.12(0.81-1.55)$ & $1.13(0.82-1.57)$ \\
\hline $\begin{array}{l}\text { Parental/other adult's } \\
\text { incarceration }\end{array}$ & $1.15(0.94-1.42)$ & $1.27(0.99-1.63)$ & $0.92(0.74-1.14)$ & $1.11(0.86-1.42)$ & $1.31(1.03-1.65)^{*}$ & $1.42(1.05-1.93)^{*}$ \\
\hline Parental divorce & $1.12(0.99-1.27)$ & $0.97(0.81-1.16)$ & $0.98(0.85-1.13)$ & $0.95(0.81-1.11)$ & $0.98(0.76-1.26)$ & $0.84(0.62-1.14)$ \\
\hline \multicolumn{7}{|l|}{ Interaction terms: Male $\mathrm{x}$} \\
\hline Psychological abuse & & $1.23(0.79-1.91)$ & & $1.16(0.78-1.74)$ & & $1.00(0.52-1.94)$ \\
\hline Physical abuse & & $1.12(0.83-1.50)$ & & $1.33(0.97-1.82)$ & & $0.82(0.51-1.31)$ \\
\hline Sexual abuse & & $1.12(0.83-1.50)$ & & $1.00(0.71-1.40)$ & & $0.84(0.52-1.37)$ \\
\hline Emotional neglect & & $0.87(0.62-1.23)$ & & $1.13(0.84-1.52)$ & & $1.37(0.90-2.09)$ \\
\hline Physical neglect & & $1.27(0.89-1.81)$ & & $0.74(0.47-1.17)$ & & $1.55(0.89-2.70)$ \\
\hline Witness of domestic violence & & $0.81(0.57-1.15)$ & & $0.90(0.61-1.33)$ & & $1.10(0.60-2.01)$ \\
\hline $\begin{array}{l}\text { Parental/other adult's substance } \\
\text { abuse }\end{array}$ & & $1.00(0.76-1.32)$ & & $1.06(0.81-1.39)$ & & $0.90(0.59-1.38)$ \\
\hline
\end{tabular}




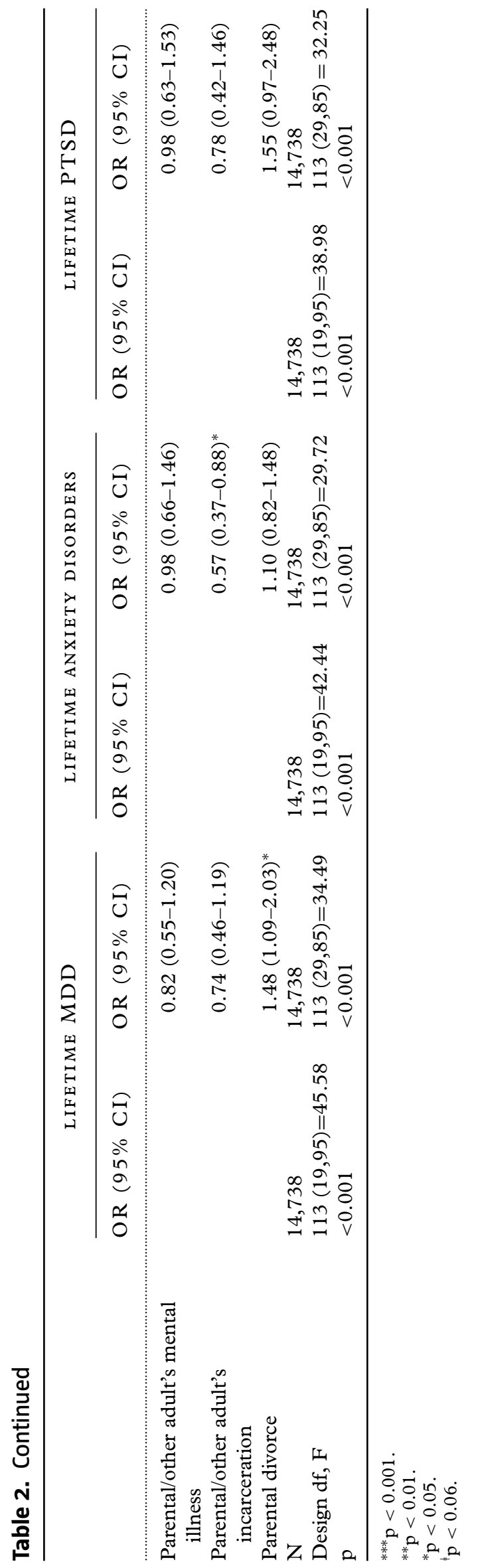

not substantially change the associations between ACEs and substance use disorders. However, for men only, physical abuse was a significant factor for alcohol use disorder and parental divorce was also a significant factor for drug use disorder and a marginally significant factor for nicotine use disorder $(p=0.055)$. The relationship between sexual abuse and drug use disorder also appears to be stronger for men than for women. Genderseparate binary logistic regression analyses (not shown in the tables) confirmed that among men only, physical abuse was significant for alcohol use disorder $(\mathrm{OR}=1.62,95 \% \mathrm{CI}=1.35-1.96)$; sexual abuse was a significant factor for drug use disorder $(\mathrm{OR}=1.60,95 \% \mathrm{CI}=1.11-2.31)$; and parental separation/divorce was a significant factor for alcohol use disorder $(\mathrm{OR}=1.22,95 \%$ $\mathrm{CI}=1.01-1.46)$, drug use disorder $(\mathrm{OR}=1.46$, $95 \% \mathrm{CI}=1.09-1.93)$, and nicotine use disorder $(\mathrm{OR}=1.32,95 \% \mathrm{CI}=1.09-1.60)$. Only among women was the association between parental/other adult's mental illness and nicotine use disorder significant $(\mathrm{OR}=1.39,95 \% \mathrm{CI}=1.07-1.80)$.

Of the control variables, older age, being Black, Hispanic, or Asian, and married/cohabiting were associated with lower odds of all three substance use disorders, and being male was associated with higher odds of all three SUDs. Having a college degree was also associated with lower odds of drug use disorder and nicotine use disorder, whereas welfare receipt before age 18 was associated with higher odds of nicotine use disorder.

\section{Association of the number of ACEs with lifetime mental and substance use disorders}

Table 4 shows that controlling for age, gender, race/ethnicity, education, marital status, and childhood economic status, a one increment increase in ACEs was associated with an increase in odds of 1.25 for $\mathrm{MDD}$ (95\% CI=1.21-1.29), 1.29 for anxiety disorder (95\% CI $=1.21-1.29), 1.45$ for PTSD (95\% CI =1.39-1.51), 1.21 for alcohol use disorder $(95 \% \mathrm{CI}=1.18-1.24), 1.27$ for drug use disorder (95\% CI $=1.22-1.32)$, and 1.19 for nicotine use disorder (95\% CI $=1.21-1.29)$. Table 4 also shows that with lifetime PTSD as a covariate, ORs for the numbers of ACEs were slightly lower but remained significant. Interaction effects between gender and the number of the ACEs were not significant for any MSUD (not shown in the tables).

\section{Discussion}

Despite much attention to the long-lasting negative impact of ACEs on adult physical/mental health 
Table 3. Adverse childhood experiences and lifetime substance use disorders among the 50+ age group: binary logistic regression results

\begin{tabular}{|c|c|c|c|c|c|c|}
\hline & \multicolumn{2}{|c|}{ LIFETIME ALCOHOL USE DISORDER } & \multicolumn{2}{|c|}{ LIFETIME DRUG USE DISORDER } & \multicolumn{2}{|c|}{ LIFETIME NICOTINE USE DISORDER } \\
\hline & OR $(95 \% \mathrm{CI})$ & OR $(95 \% \mathrm{CI})$ & OR $(95 \% \mathrm{CI})$ & OR $(95 \% \mathrm{CI})$ & OR $(95 \% \mathrm{CI})$ & OR $(95 \% \mathrm{CI})$ \\
\hline Age & $0.95(0.94-0.96)^{* * *}$ & $0.95(0.94-0.96)^{* * *}$ & $0.91(0.90-0.92)^{* * *}$ & $0.91(0.90-0.92)^{* * *}$ & $0.97(0.96-0.97)^{* * *}$ & $0.97(0.96-0.97)^{* * *}$ \\
\hline Male & $2.82(2.53-3.14)^{* * *}$ & $2.84(2.48-3.25)^{* * *}$ & $2.26(1.87-2.72)^{* * *}$ & $2.08(1.60-2.71)^{* * *}$ & $1.87(1.70-2.05)^{* * *}$ & $1.81(1.61-2.04)^{* * *}$ \\
\hline Black & $0.54(0.46-0.62)^{* * *}$ & $0.54(0.46-0.62)^{* * *}$ & $0.80(0.63-1.01)$ & $0.79(0.62-0.99)^{*}$ & $0.59(0.51-0.68)^{* * *}$ & $0.58(0.51-0.67)^{* * *}$ \\
\hline Hispanic & $0.55(0.46-0.66)^{* * *}$ & $0.55(0.46-0.66)^{* * *}$ & $0.41(0.29-0.57)^{* * *}$ & $0.41(0.29-0.57)^{* * *}$ & $0.33(0.28-0.39)^{* * *}$ & $0.33(0.28-0.39)^{* * *}$ \\
\hline Asian & $0.30(0.18-0.48)^{* * *}$ & $0.29(0.18-0.47)^{* * *}$ & $0.28(0.12-0.68)^{* *}$ & $0.28(0.12-0.67)^{* *}$ & $0.41(0.28-0.60)^{* * *}$ & $0.41(0.28-0.59)^{* * *}$ \\
\hline American Indian & $1.34(0.95-1.89)$ & $1.33(0.94-1.89)$ & $1.32(0.77-2.25)$ & $1.35(0.80-2.29)$ & $0.98(0.65-1.47)$ & $0.97(0.65-1.46)$ \\
\hline College degree & $1.05(0.93-1.18)$ & $1.04(0.92-1.18)$ & $0.73(0.60-0.90)^{* *}$ & $0.74(0.60-0.90)^{* *}$ & $0.49(0.44-0.56)^{* * *}$ & $0.49(0.44-0.56)^{* * *}$ \\
\hline Married/cohabiting & $0.74(0.67-0.83)^{* * *}$ & $0.74(0.67-0.83)^{* * *}$ & $0.55(0.47-0.65)^{* * *}$ & $0.55(0.47-0.64)^{* * *}$ & $0.62(0.57-0.68)^{* * *}$ & $0.62(0.56-0.68)^{* * *}$ \\
\hline $\begin{array}{l}\text { Family on welfare before } \\
\quad 18\end{array}$ & $1.08(0.91-1.29)$ & $1.08(0.91-1.29)$ & $1.28(0.97-1.70)$ & $1.29(0.98-1.71)$ & $1.39(1.18-1.64)^{* * *}$ & $1.40(1.19-1.65)^{* * *}$ \\
\hline \multicolumn{7}{|c|}{ Adverse childhood experiences } \\
\hline Psychological abuse & $1.14(0.94-1.38)$ & $1.25(0.94-1.67)$ & $1.48(1.08-2.03)^{*}$ & $1.40(0.86-2.28)$ & $1.26(1.04-1.54)^{*}$ & $1.29(1.02-1.63)^{*}$ \\
\hline Physical abuse & $1.38(1.19-1.59)^{* * *}$ & $1.07(0.84-1.36)$ & $1.64(1.27-2.11)^{* * *}$ & $1.56(1.06-2.27)^{*}$ & $1.44(1.25-1.65)^{* * *}$ & $1.36(1.14-1.63)^{* *}$ \\
\hline Sexual abuse & $1.51(1.26-1.82)^{* * *}$ & $1.56(1.25-1.95)^{* * *}$ & $1.32(1.04-1.66)^{*}$ & $1.13(0.84-1.52)$ & $1.16(1.01-1.43)^{*}$ & $1.16(0.99-1.37)$ \\
\hline Emotional neglect & $0.94(0.79-1.12)$ & $1.04(0.83-1.30)$ & $1.01(0.81-1.25)$ & $1.23(0.89-1.70)$ & $0.96(0.84-1.10)$ & $0.96(0.77-1.20)$ \\
\hline Physical neglect & $0.98(0.79-1.21)$ & $0.83(0.65-1.07)$ & $1.05(0.76-1.44)$ & $1.04(0.67-1.62)$ & $1.02(0.83-1.26)$ & $0.88(0.66-1.16)$ \\
\hline $\begin{array}{l}\text { Witnessed domestic } \\
\text { violence }\end{array}$ & $0.85(0.72-1.00)$ & $1.01(0.79-1.28)$ & $0.92(0.71-1.20)$ & $0.84(0.60-1.17)$ & $1.10(0.93-1.30)$ & $1.14(0.89-1.45)$ \\
\hline $\begin{array}{l}\text { Parental/other adult's } \\
\text { substance abuse }\end{array}$ & $1.83(1.60-2.10)^{* * *}$ & $1.94(1.63-2.31)^{* * *}$ & $1.59(1.33-1.90)^{* * *}$ & $1.80(1.33-2.45)^{* * *}$ & $1.45(1.29-1.62)^{* * *}$ & $1.48(1.25-1.76)^{* * *}$ \\
\hline $\begin{array}{l}\text { Parental/other adult's } \\
\text { mental illness }\end{array}$ & $1.36(1.13-1.65)^{* *}$ & $1.36(1.02-1.83)^{*}$ & $1.37(1.06-1.77)^{*}$ & $1.55(1.07-2.24)^{*}$ & $1.19(1.00-1.43) \ddagger$ & $1.41(1.10-1.82)^{* *}$ \\
\hline $\begin{array}{l}\text { Parental/other adult's } \\
\text { incarceration }\end{array}$ & $1.01(0.79-1.28)$ & $1.05(0.73-1.51)$ & $1.10(0.81-1.50)$ & $1.02(0.62-1.68)$ & $1.04(0.83-1.29)$ & $1.05(0.79-1.40)$ \\
\hline Parental divorce & $1.18(1.02-1.38)$ & $1.15(0.91-1.46)$ & $1.13(0.89-1.44)$ & $0.76(0.50-1.14)$ & $1.14(1.00-1.31)^{*}$ & $1.01(0.85-1.20)$ \\
\hline \multicolumn{7}{|l|}{ Interaction terms: Male $\mathrm{x}$} \\
\hline Psychological abuse & & $0.86(0.55-1.35)$ & & $1.12(0.60-2.10)$ & & $0.99(0.67-1.44)$ \\
\hline Physical abuse & & $1.51(1.11-2.07)^{*}$ & & $1.06(0.69-1.64)$ & & $1.10(0.83-1.47)$ \\
\hline Sexual abuse & & $0.93(0.66-1.31)$ & & $1.43(0.88-2.30)$ & & $1.01(0.73-1.40)$ \\
\hline Emotional neglect & & $0.86(0.63-1.16)$ & & $0.71(0.47-1.07)$ & & $1.00(0.74-1.35)$ \\
\hline Physical neglect & & $1.35(0.91-2.00)$ & & $1.04(0.58-1.87)$ & & $1.39(0.94-2.05)$ \\
\hline $\begin{array}{l}\text { Witnessed domestic } \\
\text { violence }\end{array}$ & & $0.71(0.49-1.02)$ & & $1.21(0.72-2.02)$ & & $0.94(0.63-1.39)$ \\
\hline
\end{tabular}




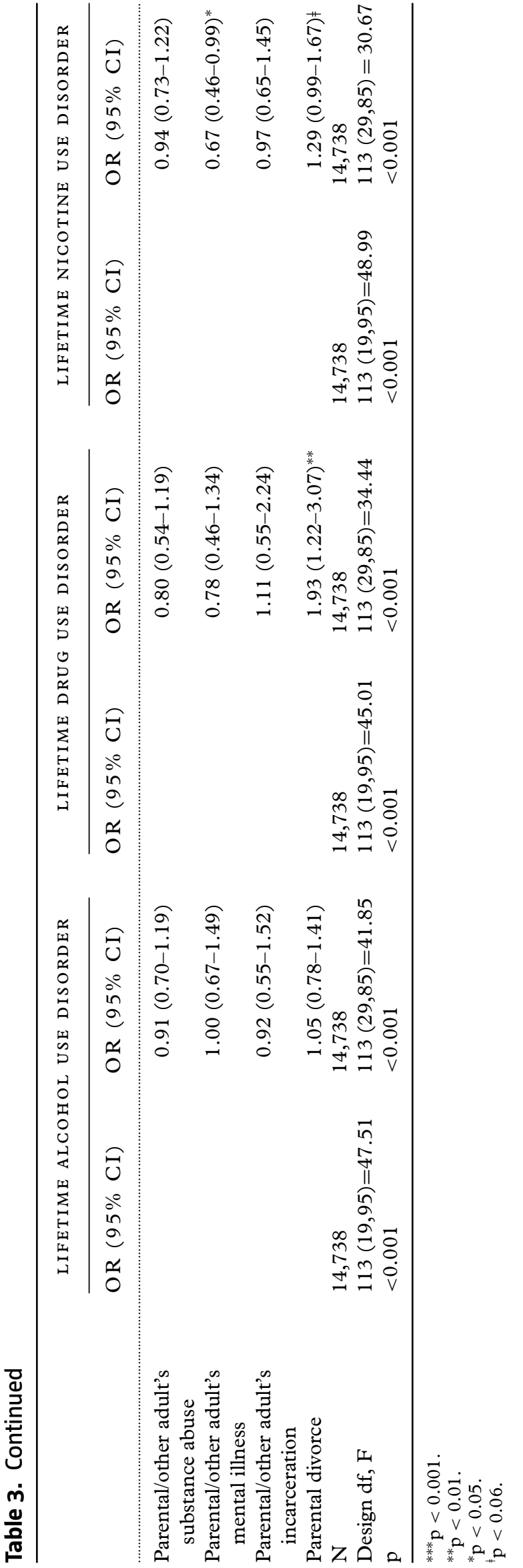

over the past two decades, little research has focused on older adults. With growing numbers of older adults with MSUDs, the present study, using recently collected nationally representative epidemiologic data, examined associations between ten types of childhood adversities and lifetime MSUDs among the $50+$ age group. The findings show that approximately one-half $(51.7 \%)$ of individuals in this age group reported experiencing one or more ACEs, and parental/other adult's substance abuse was the most prevalent ACE. In general, the rates of specific ACEs in this study were similar to the rates found for all age groups in a prior study based on the 2004-2005 NESARC (Cavanaugh et al., 2015). As previous studies of ACEs in all age groups (Edwards et al., 2003; Cavanaugh et al., 2015) also show, a higher proportion of women than men in the $50+$ age group experienced ACEs.

Our findings show that child abuse and parental/other adult's mental illness and substance abuse were significant factors for both MSUDss. In total, nine ACEs (i.e. all except parental divorce) were significantly associated with one or more lifetime mental disorders among both genders, whereas parental divorce was associated with men's MDD only. Six ACEs (i.e. three types of child abuse, parental/other adult's mental illness, parental/other adult's substance abuse, and parental divorce) were significantly associated with one or more lifetime substance use disorders for both genders. Emotional and physical neglect, witnessing domestic violence, and having an incarcerated household member were not associated with any substance use disorder. As our literature review notes, in addition to possible genetic influences of mental illness and substance abuse from parent to child, living with parents/other adults who had mental illness and/or substance abuse may have compromised child development given multiple stressors, including child abuse and neglect, which children may have experienced as a result. The findings also show that higher numbers of ACEs were associated with increased odds of having had any lifetime MSUD and that the strengths of these associations were consistent across all MSUDs. These findings generally support $\mathrm{H} 1 \mathrm{a}$ and $\mathrm{H} 2 \mathrm{a}$ but leave questions regarding potentially different impact of some ACEs on mental disorders versus substance use disorders.

As in previous studies (Keyes et al., 2012), our study indicates that the stronger relationship between ACEs and men's substance use disorders may be partially attributable to their higher substance use rates. However, contrary to previous studies, we found that the association between 
Table 4. Number of adverse childhood experiences (ACEs) and lifetime mental and substance use disorders among the 50+ age group: Binary logistic regression results

\begin{tabular}{|c|c|c|c|c|c|c|}
\hline & \multirow{4}{*}{$\begin{array}{l}\text { LIFETIME MDD } \\
\text { OR }(95 \% \text { CI })\end{array}$} & \multicolumn{2}{|l|}{ LIFETIME } & \multicolumn{2}{|l|}{ LIFETIME } & \multirow{4}{*}{$\begin{array}{l}\text { LIFETIME } \\
\text { NICOTINE USE } \\
\text { DISORDER } \\
\text { OR }(95 \% \text { CI })\end{array}$} \\
\hline & & ANXIETY & & ALCOHOL USE & LIFETIME DRUG & \\
\hline & & DISORDER & LifETIME PTSD & DISORDER & USE DISORDER & \\
\hline & & OR $(95 \% \mathrm{CI})$ & OR $(95 \% \mathrm{CI})$ & OR $(95 \% \mathrm{CI})$ & OR $(95 \% \mathrm{CI})$ & \\
\hline No. of ACEs & $1.25(1.21-1.29)^{* * *}$ & $1.29(1.25-1.32)^{* * *}$ & $1.45(1.39-1.51)^{* * *}$ & $1.21(1.18-1.24)^{* * *}$ & $1.27(1.22-1.32)^{* * *}$ & $1.19(1.16-1.23)^{* * *}$ \\
\hline $\mathrm{N}$ & 14,738 & 14,738 & 14,738 & 14,738 & 14,738 & 14,738 \\
\hline \multirow[t]{2}{*}{ Design df, F } & 113 & 113 & 113 & 113 & 113 & 113 \\
\hline & $(10,104)=87.24$ & $(10,104)=80.14$ & $(10,104)=56.96$ & $(10,104)=91.71$ & $(10,104)=82.84$ & $(10,104)=86.19$ \\
\hline \multirow[t]{3}{*}{$\mathrm{p}$} & $<.001$ & $<.001$ & $<.001$ & $<.001$ & $<.001$ & $<.001$ \\
\hline & Lifetime MDD & $\begin{array}{l}\text { Lifetime anxiety } \\
\text { disorder }\end{array}$ & & $\begin{array}{l}\text { Lifetime alcohol use } \\
\text { disorder }\end{array}$ & $\begin{array}{l}\text { Lifetime drug use } \\
\text { disorder }\end{array}$ & $\begin{array}{l}\text { Lifetime nicotine } \\
\text { use disorder }\end{array}$ \\
\hline & OR $(95 \% \mathrm{CI})$ & OR $(95 \% \mathrm{CI})$ & & OR $(95 \% \mathrm{CI})$ & OR $(95 \% \mathrm{CI})$ & OR $(95 \% \mathrm{CI})$ \\
\hline Lifetime PTSD & $3.16(2.62-3.80)^{* * *}$ & $4.45(3.64-5.44)^{* * *}$ & & $2.12(1.73-2.60)^{* * *}$ & $2.63(2.05-3.37)^{* * *}$ & $1.79(1.51-2.12)^{* * *}$ \\
\hline Number of ACEs & $1.21(1.17-1.24)^{* * *}$ & $1.23(1.19-1.27)^{* * *}$ & & $1.18(1.15-1.22)^{* * *}$ & $1.22(1.18-1.27)^{* * *}$ & $1.17(1.14-1.21)^{* * *}$ \\
\hline $\mathrm{N}$ & 14,738 & 14,738 & & 14,738 & 14,738 & 14,738 \\
\hline \multirow[t]{2}{*}{ Design df, F } & 113 & 113 & & 113 & 113 & 113 \\
\hline & $(11,103)=88.31$ & $(11,103)=86.71$ & & $(11,103)=94.22$ & $(11,103)=74.82$ & $(11,103)=93.86$ \\
\hline $\mathrm{p}$ & $<0.001$ & $<0.001$ & & $<0.001$ & $<0.001$ & $<0.001$ \\
\hline
\end{tabular}

Controls were age, gender, race/ethnicity, education, marital status, and family on welfare before age 18 .

*** $\mathrm{p}<0.001$. 
some ACEs and mental disorders was also stronger among men than among women, even though women had significantly higher rates of mental disorders than men. Though parental separation/divorce was not a factor for women's lifetime MSUDs, it was a significant factor for men's lifetime MDD. Gender differences in coping strategies (e.g. women rely more on emotional support (Tamres et al., 2002)) may help to explain the stronger associations between some ACEs and mental disorders among men than among women. However, our literature search and additional data analysis did not identify other probable reasons. Further research is needed to investigate potential causes for these gender differences. Though gender differences for specific ACEs were identified, associations between the total number of ACEs and MSUDs indicate overall, gender-neutral cumulative effects of ACEs. These findings partially support $\mathrm{H} 2 \mathrm{a}$ but not $\mathrm{H} 2 \mathrm{~b}$.

Despite significant associations between ACEs and MSUDs, the odds ratios for ACEs tended to be small, and they were smaller than the odds ratios for sociodemographic variables. Thus, it appears that the effects of ACEs may have been attenuated, though not eliminated, in this age group, possibly by age, gender, race/ethnicity, education, and marital status. Consistently significant associations of age, gender, race/ethnicity, and marital status with MSUDs suggest important biopsychosocial dimensions across the life course that should be considered in future research on long-term effects of ACEs. The finding that college education was associated with reduced odds of MDD, drug use disorder, and nicotine use disorder further underscores the important role of educational attainment and associated socioeconomic resources in mitigating the impact of early life stressors, moderating health risk behaviors, and buffering the effects of adverse events over the life course. A longitudinal study of a nationally representative sample of communitydwelling adults aged 50+years in Ireland found that later life circumstances, including marital status and income, mediated the association between early life stressors and depression in late life (Kamiya et al., 2013). More research is needed to determine how those who faced early life stressors are able to overcome these adversities.

The study has some limitations due to the use of cross-sectional data and retrospective self-reporting of childhood events. First, the relationships found in the study represent correlations, not causation. Second, self-reporting of events that occurred decades ago may be subject to recall and self-disclosure biases. Some may have blocked, forgotten, or have faded memories of events. Others may not wish to disclose some painful memories. These biases may have resulted in underestimation of ACEs and the true strength of the relationship between ACEs and MSUDs that we examined. Third, because the time order and duration of some events (e.g. parental substance abuse and physical abuse) cannot be determined, we could not examine potential mediation effects or more complex associations among MSUDs. Fourth, the effects of trauma experiences in adulthood (e.g. combat experience, death of child/spouse, own divorce, and economic hardship) as confounders in examining lifetime MSUDs could not be included in the study. Data on the onset and duration of MSUDs would have also been helpful in mapping associations among MSUDs, ACEs, and these potential confounders.

Despite these limitations, the findings have significant implications. First, prevention of childhood maltreatment and parental substance misuse, which are likely to have long-lasting negative impacts is a key in avoiding these negative consequences. Second, though ACEs may not be prevented altogether, early detection and appropriate interventions for these events through formal and informal channels of support are likely to play an important role in preventing MSUDs throughout the life course. Third, given the significant association of both emotional and physical neglect with adult mental disorders, future ACE studies should include childhood neglect as well as abuse. Although most ACEs are associated with both MSUDs, further study is also needed to elucidate why physical and emotional neglect, witnessing domestic violence, and having an incarcerated household member are associated with mental but not substance use disorders. The fourth implication, and perhaps the most important with regard to this study, is that more research is needed to investigate why ACEs seem to have greater effects on men than on women in older age and to discern the sources of gender differences in ACEs' effects.

\section{Conflict of interest}

None

\section{Description of authors' roles}

All four authors contributed to and approved the final manuscript. N. Choi, D. DiNitto, and B. Choi conceptualized the paper, contributed to the literature review, and wrote the manuscript. 
N. Choi did the statistical analyses. C.N. Marti reviewed the statistical analysis and the manuscript and commented on them.

\section{References}

Allison, P. (2015). Statistical Horizons. When Can You Safely Ignore Multicollinearity?. Available at: http://statisticalhorizons.com/multicollinearity.

Anda, R. F. et al. (2002). Adverse childhood experiences, alcoholic parents, and later risk of alcoholism and depression. Psychiatric Services, 53, 1001-1009.

Anda, R. F. et al. (2006). The enduring effects of abuse and related adverse experiences in childhood. A convergence of evidence from neurobiology and epidemiology. European Archives of Psychiatry and Clinical Neuroscience, 256, 174-186.

Bellis, M. A., Lowey, H., Leckenby, N., Hughes, K.and Harrison, D. (2014). Adverse childhood experiences: retrospective study to determine their impact on adult health behaviours and health outcomes in a UK population. Fournal of Public Health, 36, 81-91. doi: 10.1093/pubmed/fdt038

Bernstein, D. P., Fink, L., Handelsman, L. and Foote, J. (1994). Initial reliability and validity of a new retrospective measure of child abuse and neglect. American fournal of Psychiatry, 151, 1132-1136.

Brady, K. T. and Back, S. E. (2012). Childhood trauma, posttraumatic stress disorder, and alcohol dependence. Alcohol Research: Current Reviews, 34, 408-413.

Briere, J. and Elliott, D. (2003). Prevalence and psychological sequelae of self-reported childhood physical and sexual abuse in a general population sample of men and women. Child Abuse E Neglect, 27, 1205-1222. doi: 10.1016/j.chiabu.2003.09.008

Cavanaugh, C. E., Petras, H. and Martins, S. S. (2015). Gender-specific profiles of adverse childhood experiences, past year mental and substance use disorders, and their associations among a national sample of adults in the United States. Social Psychiatry and Psychiatric Epidemiology, 50, 1257-1266. doi: 10.1007/s00127-015-1024-3

Centers for Disease Control and Prevention. (2010, December 17). Adverse childhood experiences reported by adults - five states, 2009. Morbidity and Mortality Weekly Report (MMWR), 59, 1609-1613. Available at: http: //www.cdc.gov/mmwr/preview/mmwrhtml/mm5949a1.htm

Centers for Disease Control and Prevention. (2016). About Behavioral Risk Factor Surveillance System ACE Data. Available at: http:

//www.cdc.gov/violenceprevention/acestudy/ace_brfss.html

Chapman, D. P., Whitfield, C. L., Felitti, V. J., Dube, S. R., Edwards, V. J. and Anda, R. F. (2004). Adverse childhood experiences and the risk of depressive disorders in adulthood. Fournal of Affective Disorders, 82, 217-225.

Choi, N. G., DiNitto, D. M. and Marti, C. N. (2015). Alcohol and other substance use, mental health treatment use, and perceived unmet treatment need: comparison between baby boomers and older adults. American fournal on Addictions, 24, 299-307.
Cross, D., Crow, T., Powers, A. and Bradley, B. (2015). Childhood trauma, PTSD, and problematic alcohol and substance use in low-income, African-American men and women. Child Abuse E Neglect, 44, 26-35. doi: 10.1016/j.chiabu.2015.01.007

Douglas, K. R. et al. (2010). Adverse childhood events as risk factors for substance dependence: partial mediation by mood and anxiety disorders. Addictive Behaviors, 35, 7-13. doi: 10.1016/j.addbeh.2009.07.004

Dube, S. R., Felitti, V. J., Dong, M., Giles, W. H. and Anda, R. F. (2003). The impact of adverse childhood experiences on health problems: evidence from four birth cohorts dating back to 1900. Preventive Medicine, 37, 268-277.

Edwards, V. J., Holden, G. W., Felitti, V. J. and Anda, R. F. (2003). Relationship between multiple forms of childhood maltreatment and adult mental health in community respondents: results from the adverse childhood experiences study. American fournal of Psychiatry, 160, 1453-1460.

Ehlert, U. (2013). Enduring psychobiological effects of childhood adversity. Psychoneoroendocrinology, 38, 1850-1857. doi: 10.1016/j.psyneuen.2013.06.007

Felitti, V. J. et al. (1998). Relationship of childhood abuse and household dysfunction to many of the leading causes of death in adults: the adverse childhood experiences (ACE) study. American fournal of Preventive Medicine, 14, 245-258.

Finding your ACES score., n.d.. Available at: http://www.acestudy.org/yahoo_site_admin/assets/docs/ ACE_Calculator-English.127143712.pdf.

Fink, L. A., Bernstein, D., Handelsman, L., Foote, J. and Lovejoy, M. (1995). Initial reliability and validity of the childhood Trauma interview: a new multidimensional measure of childhood interpersonal trauma. American Fournal of Psychiatry, 152, 1329-1335.

Grant, B. F. et al. (2015). National Institute on Alcohol Abuse and Alcoholism National Epidemiologic Survey on Alcohol and Related Conditions-III (NESARC-III) Source and Accuracy Statement. Available at: http://www.niaaa.nih.gov/sites/ default/files/NESARC_Final_Report_FINAL_1_8_15.pdf

Kalmakis, K. A. and Chandler, G. E. (2015). Health consequences of adverse childhood experiences: a systematic review. Fournal of the American Association of Nurse Practitioners, 27, 457-465. doi: 10.1002/2327-6924.12215

Kamiya, Y., Doyle, M., Henretta, J. C. and Timonen, V. (2013). Depressive symptoms among older adults: the impact of early and later life circumstances and marital status. Aging \& Mental Health, 17, 349-357. doi: 10.1080/13607863.2012.747078.

Kessler, R. C., Berglund, P., Demler, O., Jin, R., Merikangas, K. R. and Walters, E. E. (2005). Lifetime prevalence and age-of-onset distributions of DSM-IV disorders in the national comorbidity survey replication. Archives of General Psychiatry, 62, 593-602.

Keyes, K. M. et al. (2012). Childhood maltreatment and the structure of common psychiatric disorders. The British fournal of Psychiatry, 200, 107-115. doi: 10.1192/bjp.bp.111.093062.

Lev-Ran, S., Le Strat, Y., Imtiaz, S., Rehm, J. and Le Foll, B. (2013). Gender differences in prevalence of 
substance use disorders among individuals with lifetime exposure to substances: results from a large representative sample. American fournal on Addictions, 22, 7-13. doi: 10.1111/j.1521-0391.2013.00321.x.

McCrory, E. J. and Mayes, L. (2015). Understanding addiction as a developmental disorder: an argument for a developmentally informed multilevel approach. Current Addiction Report, 2, 326-330.

Straus, M. A. (1979). Measuring intrafamily conflict and violence: the conflict tactics (CT) scales. Fournal of Marriage and Family, 41, 75-88. doi: 10.2307/ 351733

Tamayo, T., Christian, H. and Rathmann, W. (2010). Impact of early psychosocial factors (childhood socioeconomic factors and adversities) on future risk of type 2 diabetes, metabolic disturbances and obesity: a systematic review. BMC Public Health, 10, 525. doi: 10.1186/1471-2458-10-525.

Tamres, L. K., Janicki, D. and Helgeson, V. S. (2002). Sex differences in coping behavior: a meta-analytic review and an examination of relative coping. Personality and Social Psychology Review, 6, 2-30.

Whitesell, N. R. et al. (2009). Childhood exposure to adversity and risk of substance-use disorder in two American Indian populations: the meditational role of early substance-use initiation. Fournal of Studies on Alcohol and Drugs, 70, 971-981.

Wyatt, G. E. (1985). The sexual abuse of Afro-American and white-American women in childhood. Child Abuse $\mathcal{E}$ Neglect, 9, 507-519. 